\title{
Para que servem os testes de alfabetização?
}

João Batista Araujo e Oliveira*

Luiz Carlos Faria da Silva**

\section{Resumo}

0 presente trabalho analisa os testes de alfabetização disponiveis no Brasil à luz da evidência empírica sobre o tema. 0 objetivo é verificar quais competências são medidas nesses testes, os construtos sobre alfabetização implícitos ou explícitos pelos indicadores e a robustez dos itens em relação aos indicadores. Os resultados da análise permitem concluir que os diferentes testes usados no Brasil desconhecem a literatura científica sobre o tema, não dialogam entre si e, consequentemente, não avaliam os mesmos indicadores, não apresentam validade de construto nem possuem itens suficientes para medir as competências centrais da alfabetização. Em comum, esses testes compartilham e refletem a confusão conceitual entre os construtos de alfabetização e compreensão.

Palavras chave: Alfabetização. Testes. Decodificação. Compreensão. Psicometria.

\section{What is the purpose of literacy tests? Abstract}

The paper analysis the literacy tests available in Brazil using the empirical evidence about what skills are involved in learning to read. The purpose of the paper is to identify the abilities measured by these tests, the implicit or explicit constructs implied in the indicators and the robustness of the test items in relation to the indicators. The results suggest that the various tests used in Brazil ignore the current literature about learning how to read, are not consistent with each other and, as a result, do not evaluate the same indicators. They also neither present construct validity nor sufficient items to measure the central

* PhD em Educação; Presidente do Instituto Alfa e Beto. E-mail: joao@alfaebeto.org.br

** Universidade Estadual de Maringá. Departamento de Fundamentos da Educação.

E-mail: luday@uol.com.br 
skills associated to learning to read. The tests share and reflect a conceptual confusion between the constructs of reading and understanding.

Keywords: Literacy. Tests. Decodification. Understanding. Psychometrics.

\section{¿Para qué sirven los exámenes de alfabetización? Resumen}

El presente trabajo analiza los exámenes de alfabetización disponibles en Brasil a la luz de la evidencia empirica sobre el tema. Tiene por objeto verificar cuáles son las competencias que se miden en dichos exámenes, analizar los constructos sobre alfabetización implícitos o explícitos de esos indicadores y la robustez de los ítems con relación a ellos. Los resultados del análisis permiten concluir que los diferentes exámenes utilizados en Brasil desconocen la literatura cientifica sobre el tema, no dialogan entre si y, consecuentemente, no evalúan los mismos indicadores, no presentan validez de constructo ni poseen items suficientes para medir las competencias centrales de la alfabetización. Esos exámenes comparten y reflejan la confusión conceptual entre los constructos de alfabetización y comprensión.

Palabras clave: Alfabetización. Exámenes. Decodificación. Comprensión. Psicometría.

\section{Introdução}

A literatura registra dois tipos de testes usados para medir competências de alfabetização: testes que medem a capacidade de decodificação e testes que medem competências de compreensão de leitura. Os mais conhecidos são o Gray Oral Reading Test (Gort) e o Qualitative Reading Inventory (QRI), voltados para a decodificação, e o Woodcock-Johnson Passage Comprehension subtest (WJPC) e o teste de compreensão que integra o Peabody Individual Achievement Test (PIAT), focados na avaliação da compreensão. Ocasionalmente, existem testes que visam a medir ambas as competências. Estudos que comparam os desempenhos neles obtidos mostram alta correlação dos escores entre os testes que medem decodificação e baixa correlação entre os que medem compreensão. No entanto, esses mesmos estudos mostram uma elevada covariância entre competências de decodificação e de compreensão, o que sugere que muitos testes que se propõem a medir compreensão na verdade estão avaliando competências de decodificação (KEENAN; BETJEMANN; OLSON, 2008; CUTTING; SCARBOROUGH, 2006). 0 estudo dos itens que apresentam alto grau de covariância revela, ainda, que um mesmo teste pode medir competências diferentes, dependendo do nivel de capacidade de leitura da criança: para crianças que ainda estão sendo alfabetizadas, esses itens podem medir capacidades de decodificação, mas não as capacidades de compreensão. Isso é particularmente recorrente em itens do tipo "completar a palavra que falta", cuja resposta frequentemente pode ser dada por pistas conceituais. 
Embora escassa, a literatura existente sobre o tema sugere que existe um consenso entre os psicometristas a respeito do que seja alfabetizar, e, em consequência, dos construtos a ele relacionados, dos indicadores que apontam a capacidade de decodificar e das formas de medir esse construto. A forte correlação entre testes de alfabetização confirma a robustez desse consenso. 0 mesmo não ocorre em relação às habilidades de compreensão. Pearson e Ham (2005) sugerem que a maioria dos testes de compreensão foi desenvolvida muito antes de haver quadros de referência teóricos adequados para estudar o processo de compreensão. De fato, essa dificuldade ainda permanece.

Os estudos de Hoover e Gough (1990), consistentes com as conclusões das principais revisões da literatura sobre alfabetização (MORAIS; ROBILLARD; 1998; NATIONAL READING PANEL REPORT, 2000; DEHAENE, 2007; NATIONAL EARLY LITERACY PANEL, 2008), demonstram que a capacidade de ler e compreender um texto depende de dois conjuntos distintos de habilidades: decodificar as palavras e compreender a linguagem do texto.

As crianças que não têm problemas para entender a linguagem oral e que são capazes de ler com fluência e decodificar um texto não têm problemas de compreensão. Por outro lado, as crianças que apresentam problemas de compreensão sempre têm problemas ou com a capacidade de compreender a linguagem oral ou com a habilidade de decodificar (HOOVER; GOUGH, 1990 apud SEDL, 2010, p. 1).

As evidências sobre as quais repousam essas afirmações deixam claro que as competências de decodificação e compreensão são independentes entre si, e que a avaliação da capacidade de compreensão pode e deve ser feita de maneira independente da avaliação das capacidades de decodificação, especialmente, por meio de testes orais. Concorrem, também, com a definição internacionalmente aceita de alfabetização:

0 que uma criança aprende é como funciona o sistema de escrita - tanto os princípios básicos quanto os detaIhes de sua implementação. Sabemos que ela aprendeu quando ela é capaz de identificar palavras impressas como sendo uma palavra na sua linguagem oral, de forma consistente com o sistema de escrita. Para um leitor num sistema alfabético, isso significa ser capaz de ler palavras não familiares, pseudopalavras e palavras familiares. [...] É preciso aprender muito mais do que a respeito do funcionamento do código. Mas este é o evento central da alfabetização ao qual outras aprendizagens, como estratégias de compreensão, por exemplo, devem estar conectadas (PERFETTI, 2003, p.16). 
Embora haja um consenso internacional a respeito do que seja alfabetizar e das competências que se referem ao processo de alfabetização, esses conhecimentos ainda não foram incorporados nem às políticas públicas nem aos trabalhos acadêmicos nem, consequentemente, aos testes que se propõem a avaliar competências de alfabetização.

Existem no Brasil pelo menos cinco testes que se propõem a medir competências de alfabetização: a Provinha Brasil (BRASIL, 2009a, 2009b, 2009c), do Ministério da Educação (MEC) e testes organizados ou encomendados por Secretarias Estaduais de Educação, como o Sistema Permanente de Avaliação da Educação Básica do Ceará (Spaece) (Ceará), o Sistema Mineiro de Avaliação (Simave) (Minas Gerais) , os testes usados no Sistema de Avaliação de Rendimento Escolar do Estado de São Paulo (Saresp) (São Paulo) e no Rio Grande do Sul (SÃO PAULO, 2004; BRASIL, 2009b; MINAS GERAIS, 2009; RIO GRANDE DO SUL, 2009; CEARÁ, 2010). 0 Centro de Políticas Públicas e Avaliação da Educação (Caed), da Universidade Federal de Juiz de Fora, participa da elaboração de vários desses testes e a Fundação Cesgranrio participa de pelo menos um deles. Apesar de diferenças entre os testes, especialmente nos itens usados para medir competências de decodificação, todos eles partem de pressupostos bastante semelhantes, pois repousam nas definições constantes dos Parâmetros Curriculares Nacionais (PCNS). Ao mesmo tempo, nenhum dos documentos que apresentam os testes ou seus indicadores cita qualquer teste internacional ou definição de alfabetização consistente com o paradigma predominante sobre o tema, ou seja, o paradigma da Ciência Cognitiva da Leitura.

0 presente trabalho analisa esses testes para responder às seguintes perguntas: (a) o que esses testes se propõem a medir; (b) o que esses testes medem; (c) por que esses testes não medem competências de alfabetização e (d) para que servem as recomendações feitas pelos proponentes desses testes.

\section{O que medem os testes de alfabetização usados no Brasil}

0 Quadro 1 apresenta a lista de indicadores relacionados com os principais testes de avaliação da alfabetização utilizados no Brasil. A lista inclui apenas os indicadores relacionados com competências que, à luz da literatura científica, poderiam ser considerados de alguma forma associados ao conceito de decodificação. Foram excluídos itens não relevantes, como, por exemplo, a capacidade de escrever o próprio nome. A lista não inclui os itens relacionados com o conceito de compreensão que, na maioria desses testes, envolve a maioria de indicadores e itens.

Exceto no teste do Saresp ( $1^{\circ}$ ano) e do Spaece ( $2^{\circ}$ ano), os testes não especificam com clareza a série em que devem ser aplicados. A Provinha Brasil, segundo se pode inferir, pode ser aplicada em qualquer das três primeiras séries: esse fato, por si mesmo, já ilustra a dificuldade existente, no país, em lidar com o conceito de alfabetização. 
Quadro 1 - Descritores usados nos vários testes de alfabetização.

\begin{tabular}{|l|c|c|c|c|c|}
\hline Descritor & $\begin{array}{c}\text { Provinha } \\
\text { Brasil }\end{array}$ & SPAECE & SIMAVE & SAERS & RS \\
\hline Identificar letras & $\mathrm{X}$ & $\mathrm{X}$ & $\mathrm{X}$ & & $\mathrm{X}$ \\
\hline Reconhecer letras & $\mathrm{X}$ & $\mathrm{X}$ & $\mathrm{X}$ & & $\mathrm{X}$ \\
\hline $\begin{array}{l}\text { Usar maiúsculas, } \\
\text { minúsculas, cursivas }\end{array}$ & $\mathrm{X}$ & & & \\
\hline Identificar a direção da escrita & & $\mathrm{X}$ & & & \\
\hline $\begin{array}{l}\text { Ordenar a escrita } \\
\text { (disposição no papel) }\end{array}$ & & & & & $\mathrm{X}$ \\
\hline Segmentar palavras escritas & & $\mathrm{X}$ & & & \\
\hline Segmentar palavras em silabas & & & & & $\mathrm{X}$ \\
\hline Identificar rimas em textos escritos & & $\mathrm{X}$ & & $\mathrm{X}$ & \\
\hline Contar silabas & $\mathrm{X}$ & $\mathrm{X}$ & $\mathrm{X}$ & & \\
\hline $\begin{array}{l}\text { Identificar sílaba } \\
\text { no início da palavra }\end{array}$ & & $\mathrm{X}$ & $\mathrm{X}$ & & \\
\hline $\begin{array}{l}\text { Identificar sílaba } \\
\text { no meio da palavra }\end{array}$ & & $\mathrm{X}$ & & & \\
\hline Identificar som da silaba & & & $\mathrm{X}$ & & \\
\hline Decodificar palavras (sillabas CV) & $\mathrm{X}$ & $\mathrm{X}$ & $\mathrm{X}$ & $\mathrm{X}$ & \\
\hline Decodificar palavras (sillabas CVC) & $\mathrm{X}$ & $\mathrm{X}$ & $\mathrm{X}$ & $\mathrm{X}$ & \\
\hline Identificar o conceito de palavras & & $\mathrm{X}$ & & & \\
\hline Ler palavras & $\mathrm{X}$ & & & $\mathrm{X}$ & \\
\hline $\begin{array}{l}\text { Identificar e escrever palavras, } \\
\text { observando sinais de nasalização }\end{array}$ & & & & & $\mathrm{X}$ \\
\hline
\end{tabular}

Fonte: Os autores (2010).

A Provinha Brasil (BRASIL, 2009a, 2009b, 2009c), por exemplo, apresenta seis descritores: dois deles referem-se à identificação e ao reconhecimento de letras habilidades que seriam plausiveis investigar no início do processo de alfabetização. Três outras referem-se à capacidade de decodificar palavras, diferenciando-as pelo tipo de sílaba ou pelo contexto (ler palavras no contexto de uma frase). E uma delas refere-se à habilidade de contar silabas - um indicador de consciência fonológica normalmente presente em crianças de quatro anos de idade. A Prova do Simave (MINAS GERAIS, 2009) possui mais indicadores relacionados com a identificação de silabas - refletindo possivelmente um entendimento de que o código seria silábico, e não alfabético. A prova do Spaece (CEARÁ, 2010) inclui descritores adicionais relacionados com consciência fonológica. 
Desse quadro pode-se depreender que, apesar de conterem alguns elementos em comum, não existe um consenso a respeito do construto (alfabetizar), nem das competências que permitiriam mensurá-lo (decodificar), nem a respeito das formas adequadas para obter sua medida. Por exemplo, o indicador "decodificar palavras" significa diferentes competências para os diferentes testes. Raramente, como veremos adiante, a avaliação dessa competência chega ao nível do fonema - que está na base do sistema alfabético de escrita. Em outras palavras, os testes usados para avaliar a alfabetização, no Brasil, carecem não apenas de validade de construto, mas da própria especificação adequada do construto. Embora o objetivo do artigo esteja esgotado na sua essência, pode ser útil examinar as demais questões levantadas anteriormente, especialmente entender o que medem os itens usuais em testes de alfabetização no Brasil.

\section{0 que os testes medem}

A análise dos itens utilizados para avaliar essas competências ajuda a esclarecer o que esses testes se propõem a medir. 0 teste que apresenta um maior número de itens voltados para a decodificação é a Provinha Brasil - cerca de 14 dos 24 itens. Por essa razão, concentramos nossa análise nesse teste. De resto, é o teste cujos itens, apesar das deficiências já apontadas, possuem melhor qualidade. 0 Quadro 2 apresenta um exame dos itens de um desses testes - no caso, o teste do primeiro semestre de 2009 (série escolar não indicada), no item decodificação. As questões foram agrupadas para facilitar a análise e evitar repetições nos comentários.

Quadro 2 - Itens de decodificação usados na Provinha Brasil, $1^{\circ}$ semestre - 2009.

\begin{tabular}{|c|c|c|c|}
\hline Número da & A questāo & 0 que pretende medir & Observaçōes \\
\hline 1 & $\begin{array}{l}\text { Desenho de uma mala. } \\
\text { Fala, bala, mala, sala. }\end{array}$ & $\begin{array}{l}\text { Se a criança associa o } \\
\text { fonema } / \mathrm{m} / \text { para } \\
\text { identificar a palavra } \\
\text { mala. }\end{array}$ & $\begin{array}{l}\text { A criança pode conhecer a } \\
\text { forma visual da palavra, por } \\
\text { se tratar de palavra de alta } \\
\text { frequência. }\end{array}$ \\
\hline 3 & $\begin{array}{l}\text { Desenho de um animal. } \\
\text { Gato, Pato, Rato, Tato. }\end{array}$ & Idem acima. & Idem acima. \\
\hline 7 & $\begin{array}{l}\text { Desenho de uma cama. } \\
\text { M S C N }\end{array}$ & Idem acima. & Idem acima. \\
\hline 4 & $\begin{array}{l}\text { Desenho de bicicleta. } \\
\text { Bicicleta biscoito picolé } \\
\text { piscina. }\end{array}$ & $\begin{array}{l}\text { Capacidade de } \\
\text { identificar } \\
\text { corretamente a palavra } \\
\text { correspondente ao } \\
\text { desenho. }\end{array}$ & $\begin{array}{l}\text { Aluno pode identificar } \\
\text { palavra globalmente. Os } \\
\text { itens do teste sugerem que } \\
\text { se trataria de saber } \\
\text { discriminar entre B e P e, } \\
\text { além disso, bicicleta de } \\
\text { biscoito. }\end{array}$ \\
\hline
\end{tabular}




\begin{tabular}{|c|c|c|c|}
\hline 6 & $\begin{array}{l}\text { Desenho de panela. } \\
\text { Caneta, janela, peteca, } \\
\text { panela. }\end{array}$ & $\begin{array}{l}\text { Capacidade de identificar } \\
\text { corretamente a palavra } \\
\text { correspondente ao } \\
\text { desenho. }\end{array}$ & $\begin{array}{l}\text { Idem acima. } 0 \text { teste sugere } \\
\text { que } 0 \text { aluno precisaria } \\
\text { discriminar janela de panela } \\
\text { e panela de peteca. }\end{array}$ \\
\hline 8 & $\begin{array}{l}\text { Desenho de formiga. } \\
\text { Farmacinha, } \\
\text { formiguinha, viuvinha, } \\
\text { vovozinha. }\end{array}$ & Idem acima. & $\begin{array}{l}0 \text { teste coloca terminações } \\
\text { semelhantes para induzir o } \\
\text { aluno a se concentrar na } \\
\text { parte inicial da palavra. }\end{array}$ \\
\hline 9 & $\begin{array}{l}\text { Desenho de cachorro. } \\
\text { Cabrito, cachorro, } \\
\text { camelo, cavalo. }\end{array}$ & Idem acima. & $\begin{array}{l}\text { O teste sugere que para ler a } \\
\text { palavra o aluno precisaria ir } \\
\text { além da sílaba inicial (ca). } \\
\text { que é igual em todas as } \\
\text { palavras. }\end{array}$ \\
\hline 10 & $\begin{array}{l}\text { Desenho de lata. } \\
\text { Lama, lapa, lara, lata. }\end{array}$ & Idem acima. & $\begin{array}{l}\text { O teste sugere que, para ler a } \\
\text { palavra, o aluno precisaria ir } \\
\text { além da sílaba inicial (ca). } \\
\text { que é igual em todas as } \\
\text { palavras. }\end{array}$ \\
\hline 15 & $\begin{array}{l}\text { Desenho de borboleta. } \\
\text { Bor bo le ta. }\end{array}$ & $\begin{array}{l}\text { Aluno deve numerar as } \\
\text { sílabas em ordem para } \\
\text { formar a palavra. }\end{array}$ & $\begin{array}{l}\text { Não se refere a nenhuma } \\
\text { competência conhecida de } \\
\text { decodificaçăo. }\end{array}$ \\
\hline 13 & $\begin{array}{l}\text { Figura de jacaré, } \\
\text { Galinha, janela, } \\
\text { chácara, jiboia. } \\
\text { Professor lê uma frase. } \\
\text { Aluno deve identificar } \\
\text { a frase lida entre } \\
\text { quatro frases } \\
\text { semelhantes. }\end{array}$ & $\begin{array}{l}\text { Aluno deve identificar } \\
\text { qual palavra começa } \\
\text { igual à figura. } \\
0 \text { aluno precisa saber } \\
\text { identificar } \\
\text { corretamente as } \\
\text { palavras lidas. }\end{array}$ & $\begin{array}{l}\text { Questão mistura conceito de } \\
\text { fonema com conceito de } \\
\text { sílaba inicial. } \\
0 \text { aluno só saberá a resposta } \\
\text { correta se souber ler. }\end{array}$ \\
\hline 2 & $\begin{array}{l}\text { Colocar letras em } \\
\text { ordem alfabética. }\end{array}$ & $\begin{array}{l}\text { Colocar letras em } \\
\text { ordem alfabética. }\end{array}$ & $\begin{array}{l}\text { Competência não mede } \\
\text { capacidade de decodificar } \\
\text { nem conhecimento de letras. } \\
\text { A criança precisa conhecer } \\
\text { as letras, o que é relevante } \\
\text { para decodificar, mas não } \\
\text { precisa conhecer a ordem } \\
\text { alfabética. } \\
\end{array}$ \\
\hline 5 & $\begin{array}{l}\text { Quadros com letras, } \\
\text { números, palavras, } \\
\text { figuras. } \\
\text { Aluno deve dizer qual } \\
\text { só tem letras. } \\
\end{array}$ & $\begin{array}{l}\text { Distinguir letras de } \\
\text { outros símbolos. }\end{array}$ & $\begin{array}{l}\text { Não é competência de } \\
\text { alfabetização propriamente } \\
\text { dita, embora seja essencial o } \\
\text { aluno identificar as letras. }\end{array}$ \\
\hline 14 & $\begin{array}{l}\text { Palavras escritas com } \\
\text { letras bastão e cursiva, } \\
\text { maiúscula e minúscula. }\end{array}$ & $\begin{array}{l}\text { Não é possivel inferir o } \\
\text { comando, mas deve ser } \\
\text { para identificar um } \\
\text { determinado tipo de letra } \\
\text { (bastão ou cursiva) e se é } \\
\text { maiúscula ou minúscula. }\end{array}$ & $\begin{array}{l}\text { Não é competência de } \\
\text { alfabetização ou } \\
\text { decodificação. }\end{array}$ \\
\hline
\end{tabular}

Fonte: Os autores (2010). 
A análise apresentada na última coluna do Quadro 2 sugere que apenas dois itens avaliam, efetivamente, competências de decodificação: o item 16 (identificar uma frase lida) e o item 7, em que o aluno identifica o fonema (inicial, no caso). E, nesses dois indicadores, há apenas um item de cada tipo - o que não permite gerar informações suficientes sobre o domínio dos fonemas. Inexistem itens que usem pseudopalavras reconhecidamente a forma mais adequada para avaliar competências de decodificação - e itens que comprovem que o aluno domina as duas competências centrais da decodificação, a habilidade de análise e síntese de fonemas (ADAMS, 1990; KAHMI, 2009a).

A maioria dos outros itens que apresentam palavras pode ser respondida por adivinhação ou reconhecimento visual ou global da palavra, por se tratarem de palavras de uso frequente ou que podem ser identificadas por meio de pistas ortográficas. Alguns itens medem competências necessárias, mas não centrais ao processo de decodificação, tais como a habilidade de identificar letras e discriminá-las de outras formas de escrita. E vários itens repousam numa concepção de que existe um estágio silábico de alfabetização, crença incisiva e reiteradamente superada pelas evidências científicas (POLLO; TREIMAN; KESSLER, 2008, 2009, 2010).

A Figura 1 apresenta um modelo de descritores de alfabetização consistente com o paradigma da ciência cognitiva da leitura.

Figura 1: Descritores de alfabetização.

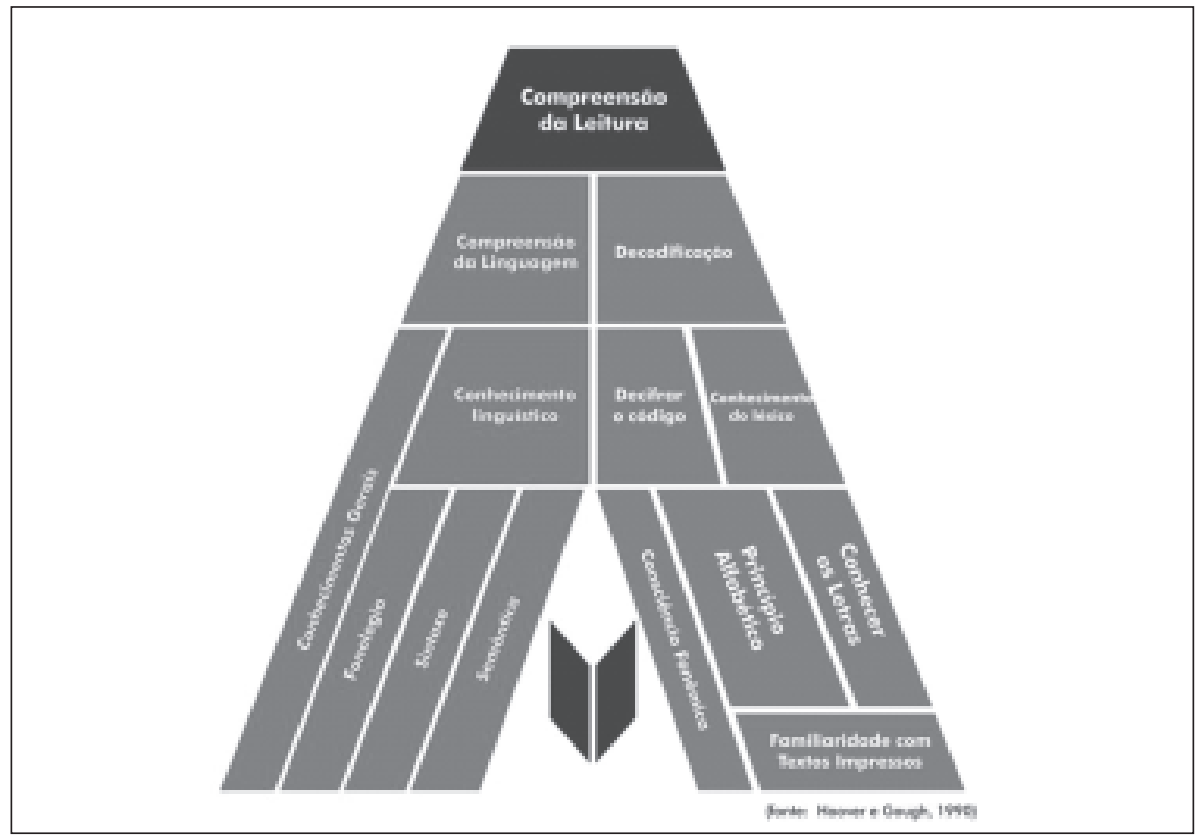

Fonte: Hoover e Gough (1990). 
Esse modelo foi desenvolvido por Hoover e Gough (1990) e é acompanhado por inúmeras sugestões de testes e tipos de itens que avaliam essas competências. Podese observar o fosso que separa as concepções que orientam a elaboração de matrizes e testes, no Brasil, das concepções refletidas na literatura científica sobre o tema.

\section{Por que esses testes não medem competências de alfabetização?}

A análise da documentação que acompanha esses testes e da fundamentação nela apresentada deixa claro por que os testes não medem competências que permitem avaliar, com objetividade e precisão, se o aluno domina as competências básicas de alfabetização. Apoiamo-nos aqui em uma amostra desses documentos que está citada na bibliografia, Na sua essência, são todos muito parecidos. Resumimos a análise em três pontos principais.

\section{A concepção de alfabetização}

Numa série de artigos publicados sobre o tema, Kahmi (2009a, 2009b) sintetiza a questão utilizando os termos "concepção ampla e concepção estrita de leitura". A concepção estrita define a leitura como processo de identificar palavras (ou decodificar). A concepção ampla define a leitura como processo de compreensão de texto. Essa definição não se aplica ao processo de alfabetização, na medida em que a compreensão é independente do processo de leitura propriamente dito. A elevada correlação entre compreensão oral e compreensão a partir da leitura feita pelo próprio aluno é evidência da independência dos conceitos de leitura e compreensão. A evidência abundante na literatura sobre a capacidade de compreensão dos disléxicos comprova, ademais, a independência desses dois construtos (MORAIS, 1994).

Essa distinção conceitual reforça a importância de isolar e priorizar a avaliação das competências da decodificação, especialmente nos anos iniciais do aprendizado da leitura. As dificuldades já mencionadas para definir o que seja e especificar as competências relacionadas com compreensão reforçam as vantagens dessa separação. A covariância demonstrada na comparação dos testes de decodificação e leitura, especialmente com leitores iniciantes, também reforça essa tese.

No Brasil, especialmente desde a introdução dos PCNs de alfabetização, a noção de decodificação foi abolida ou relegada a um plano secundário, ora considerada como algo mecânico, reducionista, desnecessário, ora como um subproduto automático do processo mais nobre, que seria o "letramento". 0 argumento usado naquele documento e nos que fundamentam os testes aqui analisados vem quase sempre apresentado numa linguagem ambígua e que vai em duas direções. De um lado, diz-se que decodificar é algo mecânico, reducionista. A alfabetização é muito mais do que decodificar. De outro lado, diz-se, nesse e em documentos dele derivados, que a alfabetização não é só decodificar ou é também decodificar, mas em nenhum momento se dá a atenção 
específica a esse aspecto, como se ele não fosse essencial. Essa dificuldade em reconhecer a centralidade da decodificação decorre do conceito de "letramento". Apesar da inconsistência lógica e empírica desse conceito, a ideia de que alfabetização e compreensão (letramento) seriam indissociáveis predomina em praticamente todas as publicações oficiais e acadêmicas sobre o tema. Ora, se letramento e alfabetização fossem indissociáveis, a pessoa não poderia se "letrar" nem antes nem depois da alfabetização. 0 argumento da indissociabilidade, portanto, é ilógico. Apesar disso, o termo letramento - que não é definido com clareza em nenhum documento que trata do tema torna-se, dessa forma, o único objetivo da alfabetização. A decodificação seria um subproduto quase que automático, de segunda categoria. E qualquer tentativa de ensino do código só é admissivel se embebida no contexto de letramento, em atividades "significativas" e contextualizadas. Essa ideia, inclusive, dificulta a avaliação de determinadas competências, por exemplo, num item para avaliar se o aluno conhece a ordem alfabética, 0 aluno deve identificar letras numa agenda.

\section{A validade dos testes}

Para ser tecnicamente adequada, do ponto vista psicométrico, uma matriz com indicadores deve ter validade de construto. Uma matriz só pode ser validada se for baseada em construtos empiricamente verificáveis. Todas as matrizes utilizadas no Brasil para avaliar a alfabetização se baseiam em construtos que não apenas são mal especificados e inconsistentes com o conhecimento científico sobre o tema, mas também não foram validados empiricamente. Mas, não se trata apenas de uma questão de validação empírica: esses testes violam os princípios mais elementares da psicometria. Para se elaborar um teste, é necessário, antes de tudo, definir o âmbito do desempenho visado. Isso se faz, normalmente, a partir do juízo de especialistas qualificados nesse âmbito de conteúdo, apoiado pela literatura relevante a seu respeito. A partir daí, se elabora um quadro estruturado, para realizar a tarefa de enquadrar itens no âmbito do conteúdo, definir o peso e quotas de cada um e identificar itens relevantes. É isso que, uma vez bem feito, precisa ser validado. Cabe aos especialistas identificar um comportamento adequado como critério de referência, para depois, obter uma medida do desempenho dos examinados nesse critério. Análise posterior, com dados individuais dos examinandos, permitirá verificar a relação entre os escores na prova e o desempenho no critério, para o conjunto dos examinados. Todos esses requisitos psicométricos básicos são sistematicamente violados nos testes examinados.

\section{A ideia de uma ciência da alfabetização}

Há pelo menos 30 anos, a comunidade científica internacional compartilha um paradigma de alfabetização baseado nas evidências da ciência cognitiva da leitura. Esse paradigma vem sendo refinado a partir dos estudos seminais de Stanovich (2000), consolidados por Adams (1990) e revistos em profundidade pelos painéis internacionais que se debruçaram sobre o tema. A Academia Brasileira de Ciências (2009) reconhece esse paradigma e insta a comunidade cientifica brasileira a levar em conta esses achados. Rejeitar esses fatos cientifi- 
cos implica rejeitar a ciência como instrumento de avanço de conhecimento. Os testes de alfabetização que circulam no Brasil não compartilham da ideia de que a ciência é universal e que os paradigmas científicos evoluem. Eles se encontram estagnados no tempo e mesmerizados por paradigmas superados há décadas pelas novas evidências.

\section{As recomendações contidas nos Manuais dos Testes}

Alguns dos testes analisados no presente artigo são acompanhados de extensos e detalhados manuais de orientação. Esses manuais são dirigidos aos professores, sugerindo que a intenção dos testes é voltada para identificar indicadores importantes do processo de alfabetização do que os seus resultados. De posse dos resultados, os professores saberiam quais competências são falhas e precisariam ser desenvolvidas.

Conforme se pode depreender da análise dos itens utilizados nas provas, como ilustrado no Quadro 2, esses testes têm pouca ou nenhuma utilidade prática para um professor alfabetizador. Uma simples comparação dos indicadores utilizados no Brasil (Quadro 1) com os indicadores propostos na literatura internacional (Figura 1) comprova esse argumento.

Um desses manuais, por exemplo, analisa o fato de o aluno escrever ou não o próprio nome como indicador de progresso ou falta de progresso no processo da alfabetização. Outro manual sugere que, quando o aluno tem dificuldade para identificar um fonema ou uma palavra, ele precisa ser alfabetizado com o uso de textos que criem contextos interessantes e motivadores. Esse tipo de recomendação, típica desses manuais, encontra-se na contramão dos estudos sobre limitações da memória e sobrecarga cognitiva, que sugerem o contrário e alertam para os riscos da excessiva contextualização. A inexistência de palavras não familiares e abstratas, nesses testes, além da inexistência de itens que permitam a leitura de pseudopalavras, reforça o caráter ideológico das recomendações. Ideológico, pois elas se baseiam numa visão ideológica, e não numa visão científica do processo de alfabetização.

Como os testes se baseiam numa visão a-científica da alfabetização, o mesmo acontece com as recomendações. Citamos apenas algumas, a título de exemplo:

A competência C3- Aquisição de consciência fonológica merece destaque, uma vez que os alunos ampliaram a habilidade de identificar o número de sílabas que compõem uma palavra, conseguindo, por exemplo, reconhecer monossílabos como palavras compostas por apenas uma sílaba. Em relação a essa competência ainda, o reconhecimento de sílabas canônicas (CV) no meio de palavra trissílaba começa a se configurar neste nível. Ressalte-se que as duas habilidades citadas são mais complexas no processo de consciência fonológica (MINAS GERAIS, 2009, p. 34). 
Assim, além de trabalhar com a contagem do número de sílabas de uma palavra (especialmente de palavras monossílabas e polissilabas), que tendem a ser mais dificeis para os alfabetizandos contarem, com a identificação de sílabas de diversos padrões (CV, CVC, CCV, V, VC...) e em diferentes posições (inicial, medial e final), sugere-se o trabalho com fonemas, especialmente com fonemas em início de palavra [...] Ressalte-se que o enfoque na sílaba ou fonema, por exemplo, deve ser feito a partir de textos lidos e efetivamente compreendidos por crianças (MINAS GERAIS, 2009, p. 36).

Contraste com as recomendações de Hoover e Gough (1990) sobre o ensino de consciência fonológica:

- Discriminar entre duas palavras de som semelhante (pato e gato) (mato-moto), (bola-bota).

- Os pares de palavras não precisam ser palavras reais ou familiares, pois nesse caso a atenção das crianças se concentra nas palavras, e não no seu sentido.

Outra caracteristica das recomendações é seu caráter pouco aderente à realidade das escolas: por cobrirem um amplo espectro de objetivos para até três séries escolares num mesmo teste, sugerem, por exemplo, que um aluno, em etapa inicial de alfabetização, poderia escrever textos. Muitos professores, influenciados por esse tipo de cobrança, acabam dedicando tempo exagerado à vã tentativa de ensinar as crianças a redigirem textos antes de alfabetizá-las. Ou seja: ao invés de ajudar a entender o processo de aprendizagem da escrita, os testes podem contribuir para conturbar ainda mais o entendimento desse processo, e das competências básicas que o aluno deve dominar antes de ser cobrado em níveis mais complexos de desempenho!

\section{Conclusão}

Os governos e a comunidade acadêmica, no Brasil, continuam à margem do progresso científico no que se refere ao estudo científico da alfabetização. Os testes disponíveis para avaliar essas competências se baseiam em concepções equivocadas sobre o processo de alfabetização, não possuem validade de construto e não constituem instrumentos psicometricamente adequados para avaliar aquilo a que se propõem. Em consequência, as recomendações feitas a partir deles padecem dos mesmos problemas e continuam a perpetuar práticas pouco eficazes de alfabetização. É relativamente fácil entender como o MEC ou Secretarias de Educação possam se tornar reféns de ideologias e pautar suas recomendações em função disso. Resta entender o que move a comunidade científica e as instituições especializadas que participam da elaboração desses testes a ignorar os avanços da ciência e identificar mecanismos institucionais que poderiam ser utilizados para promover o diálogo da comunidade científica do Brasil com a comunidade científica internacional. 


\section{Referências}

ACADEMIA BRASILEIRA DE CIÊNCIAS. Relatório do grupo de trabalho sobre educação infantil e alfabetização. Rio de Janeiro, 2009.

ADAMS, M. J. Beginning to read: thinking and learning about print. Cambridge: MIT Press, 1990.

BRASIL. Ministério da Educação. Provinha Brasil: caderno do aluno: teste 1. Brasilia: MEC: SEB: INEP, 2009a. Disponivel em: <http://www.oei.es/salactsi/ provabrasil_matriz.pdf>. Acesso em: 4 nov. 2011.

- Ministério da Educação. Provinha Brasil: matriz de referência. Brasília: MEC: INEP, $2009 b$.

Ministério da Educação. Provinha Brasil: reflexões sobre a prática. Brasilia: MEC: INEP, $2^{\circ}$ sem. 2009c.

CEARÁ (Estado). Secretaria de Educação. Relatório do SPAECE-Alfa 2009. Fortaleza, 2010.

CUTTING, L. E.; SCARBOROUGH, H. S. Prediction of reading comprehension: relative contributions of word recognition, language proficiency, and other cognitive skills can depend on how comprehension is measured. Scientific Studies of Reading, Cameron, v.10, n. 3, p. 277-299, 2006.

DEHAENE, N. Les neurones de la lecture. Paris: Odile Jacob, 2007.

NATIONAL EARLY LITERACY PANEL. Developing Early Literacy. Washington, DC: National Institute for Literacy, 2008.

HOOVER, W. A.; GOUGH, P. B. The simple view of reading. Reading and writing, New York, n. 2, p. 127-160, 1990.

KAHMI, A. G. The case for the narrow view of reading. Language, Speech and hearing Services in Schools, Washington, v. 40, p. 174-17, Apr. 2009a.

Solving the reading crises: take 2: the case for differentiated assessment. Language, Speech and hearing Services in Schools, Washington, v. 40 , p. $212-215$, apr. 2009 b.

KEENAN, J. M.; BETJEMANN, R. S.; OLSON, R. K. Reading comprehension tests vary in the skills they assess: differential dependence on decoding and oral comprehension. Scientific Studies of Reading, Cameron, v. 12, n. 3, p. 281-300, 2008. 
MINAS GERAIS. Secretaria de Estado da Educação. Boletim pedagógico 16: Proalfa. Belo Horizonte, 2009.

MORAIS, J. A arte de ler. São Paulo: UNESP, 1994.

MORAIS, J.; ROBILLARD, G. Apprendre à lire au cycle des apprentissages fondamentaux (GS, CP, CE1): analyses, réflexions et propositions. Paris: Éditions Odile Jacob: Centre National de Documentation Pédagogique, 1998.

NATIONAL READING PANEL REPORT. Teaching children to read: An evidencebased assessment of the scientific literature on reading and its implications for reading instruction. Bethesda, MD: National Institute of Child Health and Human Development, 2000.

PEARSON, P. D.; HAMM, D. N. The assessment of reading comprehension: a review of practices - past, present, and future. In: PARIS, S. G.; STAHL, A. (Ed.). Children's reading comprehension and assessment. Mahwah, NJ: Erlbaum, 2005. p. 13-69.

PERFETTI, C. A. The universal grammar of reading. Scientific Studies of Reading, Cameron, v. 7, n. 1, p. 3-24, 2003.

POLLO, T. C.; KESSLER, B.; TREIMAN, R. Statistical patterns in children's early writing. Journal of Experimental Child Psychology, [S.I.], v. 104, n. 4, p. 410-426, 2009.

POLLO, T. C.; TREIMAN, R.; KESSLER, B. Children's initial spelling strategies: bear is not bigger than 'mosquito'. In: ANNUAL MEETING, 17., 2010, Berlin. Abstracts... Berlin: Society for the Scientific Study of Reading, 2010. p. 7-10.

POLLO, T. C.; TREIMAN, R.; KESSLER, B. Preschoolers use partial letter names to select spellings: evidence from Portuguese. Applied Psycholinguistics, Cambridge, v. 29, p. 195-212, 2008.

RIO GRANDE DO SUL (Estado). Secretaria Estadual de Educação. Matriz de referência da proposta curricular: leitura e escrita: $1^{\circ}$ e $2^{\circ}$ anos: projeto para alfabetização de crianças com seis e sete anos. Porto Alegre, 2009.

SÃO PAULO (Estado). Secretaria Estadual de Educação. Prova de leitura e escrita: 1ª. série. São Paulo, 2004.

SEDL. Southern Educational Developmental Laboratory: advancing research, improving education. Disponivel em: <http:// www.sedl.org>. Acesso em: 20 set. 2010.

STANOVICH, K. E. Progress in understanding reading: scientific foundations and new frontiers. New York: Guilford Press, 2000.

Recebido em: 18/04/2011

Aceito para publicação em: 26/08/2011 